\title{
La condición transfinita del hombre en García Bacca
}

\section{El hombre "transfinito"}

Entre la abundante producción escrita del filósofo hispano-venezolano J.D. García Bacca, el pensamiento sobre el hombre ocupa un lugar medular y destacado. Pero es un pensamiento que ha ido evolucionando de forma permanente, en correspondencia con la evolución de toda su filosofía.

En diferentes trabajos anteriores he descrito las diferentes etapas de su pensamiento filosófico y antropológico' ${ }^{1}$. En estas páginas quiero ahondar en las facetas más significativas de la idea de transfinitud_humana. Posiblemente constituya esta idea el rasgo más genuino y específico del pensamiento antropológico de García Bacca (GB), rasgo presente a lo largo de toda su dilatada trayectoria filosófica, en todas sus etapas, como veremos a a continuación.

Si en cada una de ellas recompone y envuelve su personal manera de pensar con ropajes diversos, fruto de las coyunturales influencias que experimenta, uno de los rasgos más genuinos y constantes de su fondo filosófico personal es la idea de la transfinitud del hombre y, por su medio, de toda la realidad. El objetivo de este trabajo, en consecuencia, voy a desglosarlo en las siguientes partes: (a) explicitación de las diferentes etapas por las que atraviesa la obra de $\mathrm{GB}$, la concepción transfinita de lo humano; (b) mostrar los rasgos comunes que subyacen a las reales, y a veces ficticias, diferencias que conforman su personal concepción de lo humano, y (c) señalar, como conclusión, la originalidad de su pensamiento antropológico, la multitud de influencias que en ello ha experimentado, las limitaciones que conlleva y los interrogantes que plantea esta peculiar forma de entender al hombre.

\section{Las etapas de su concepción antropológica}

El pensamiento de GB se caracteriza, entre otros muchos rasgos específicos, por su condición proteica. Ello hay que achacarlo no a una supuesta inestabili- 
dad voluble, cuanto a una búsqueda incesante de la verdad y a una inquebrantable vocación de sinceridad².

A lo largo de su dilatada existencia como filósofo (nació en Pamplona, 1901, y murió en Quito, 1992), su pensamiento se ha ido plasmando a través de las siguientes etapas o andaduras intelectuales: (1) La elapa de juventud gira alrededor del neotomismo, como consecuencia de su formación filosófico-teológica de sus años de religioso clareliano. Abarca desde sus primeros trabajos escritos (1928) hasła la guerra civil española (1936-39). (2) La segunda etapa (19391947) se sitúa en la órbita de la influencia de Ortega y su "raciovilalismo", al igual que del historicismo de W. Dillhey. (3) La tercera (1947-1970) se vertebra alrededor de la influencia del "existencialismo" de M. Heidegger. (4) La cuarta (1960-1980) tiene como centro estructurador del pensamiento el "humanismo socialista" de K. Marx. Sin ninguna duda constituye esta etapa el momento cumbre de madurez del pensamiento filosófico de GB, y es en estos años cuando escribe sus obras más logradas. (5) Y la etapa quinta y definitiva (1980-1992) se halla construida alrededor de lo que podemos llamar una concepción "tecnocéntrica" del hombre y de la realidad.

En cada una de estas etapas, el pensamiento antropológico irá constituyendo uno de los nervios centrales, si no el central, del todo su edificio arquitectónico intelectual.

\subsection{La estructura transfinita del hombre}

La concepción del hombre desde la categoría de "Iransfinito" aparece en GB en sus primeros trabajos escritos tras la guerra civil española. En su "Autobiografía intelectual" nos señala que el primer choque científico que recibió contra su fondo filosófico provino de la noción de "transfinito" de Cantor", a través de la lectura de "Einleitung in die Mengenlehre" de Fränkel, cuando todavía no tenía más que 27 años (1928).

La crisis personal e ideológica que supone para el joven filósofo exiliado la contienda bélica, con su consiguiente salida de su patria y afincamiento en Quito, la resuelve ideológicamente con la construcción de su primer sistema filosófico personal, expresado en "Iniciación a filosofar" (1939), "Invitación a filosofar" (2 vols., 1940-42) y "Tipos históricos de filosofar físico, desde Hesíodo hasta Kant" (1944)4. El texto clave para la concepción antropológica del "transfinito" es el segundo de los textos indicados.

La idea que el hombre moderno liene de sí mismo, según GB, es la de experimentarse colocado entre dos realidades extremas que lo mantienen en angustiante tensión: la nada y el infinito. De esta tensión nace su radical dinamismo y su condición demontaca, definida "por no respetar lo hecho y definitivo, por no inclinarse ante el ser; y en el ser, ante la sustancia"s. 
Ya Platón había descubierto esta condición demoníaca de la condición humana, al igual que Nietzsche, constituyendo ambos autores la fuente de inspiración de nuestro autors.

La realidad humana escapa a cualquier condición "natural", que la encierre y defina de modo permanente, constituyendo su ser una incansable tensión dinámica que lo empuja a escapar de cualquier estruclura cerrada y lo lanza hacia la única meta que lo pueda contentar: ser Dios en persona, esto es, serlo todo sin que nada lo limite. Esto supone la consciente aceplación de la "muerte de Dios", proclamada por Nietzsche, y su consecuente proclamación del hombre como único absoluto.

Esto implica que consolarse con ser lo que uno es de modo definifivo, y aceptar su condición de mortal, es renunciar de entrada a ser hombre auténtico. Ser hombre es no aceptar ninguna condición como "natural", y vivir rompiendo moldes, barreras y encorsetamientos entitativos y existenciales. Su condición se resume en apuntar a e intentar ser Dios en persona. Para GB queda, pues, claro que la perspectiva biblica de entender al hombre como hecho a "imagen y semejanza de Dios" no es suficiente. No da para mucho, dice castizamente GB. Así que el hombre no puede contentarse más que con ser Dios en persona. Esa fue precisamente la pretensión de Luzbel, el príncipe de los demonios, pretensión más de acuerdo con la genuina realidad del hombre que la servil del arcángel Miguel, porque "querer ser Dios no es el mayor de los pecados, sino la mayor de las tragedias íntimas de una cosa"7.

El hombre se halla, por tanto, descoyuntado por una fuerza que lo empuja hacia serlo todo en plenitud (entificación), pero también hacia la nada y la dejación de ser (aniquilación).

La demostración concreta y existencial de esta condición transfinita se halla en que el hombre se siente constreñido, como un gas dentro de un recipiente constringente, por su estado de pura facticidad. $Y$ va siendo consciente de que no está condenado a ser definitivamente finito, a medida de que va experimentando diversos golpes propinados contra sus límites. De ahí que vaya advirtiendo que su condición de finitud es provisional, y, por tanto, superable. "La tragedia de vivir endemoniado, señala GB, consiste, pues, en tener conciencia de que se tiende a un límite inaccesible, que uno se acerca indefinidamente a él, que no hay barreras concretas infranqueables; pero que siempre surge una nueva, franqueable a su vez. Lo que no es franqueable ni superable es la necesidad de que en cada momento hay una barrera u otra"s.

Este esfuerzo permanenle de romper barreras y apuntar a lo infinito le sumirá en una permanente "agonía" (lucha), como si llevara el infiemo a cuestas. En esta lucha contra sus límites, el obstáculo más firme es su propio cuerpo, definido como "la materia actuando como límite de la transfinitud del hombre auténti- 
co, del hombre interior"'. Aquí se advierte la concepción dualista que del hombre tiene GB en esta etapa de su pensamiento", puesto que "la materia en sí [sigue diciendo], no entra en la esencia del hombre, sino en cuanto barrera a superar por la transfinitud"'". La esencia de lo humano se halla, por tanto, en su interioridad, y se reduce a ese deseo de atravesar cualquier barrera o límite que coarte y se oponga a su capacidad expansiva. El hombre necesita apoyarse en una realidad corpórea para seguir siendo, pero pudiera llegar a darse una situación en la que su cuerpo físico-químico actual pudiera ser sustituido por otro más espiritual, de naturaleza conceptual, constiluyéndose en un nuevo límite de lo transfinito, pues "tal vez las ideas sirvan entonces como de límite, de una manera más honda y próxima que en este mundo"12.

Como puede verse, esta condición transfinita y demoníaca, que constituye la estruclura que conforma nuestra manera de ser hombres, y que la recibimos como don de la naturaleza, se convierte, a su vez, en una tarea a emprender y llevar a cabo, puesto que, como nos advierte GB, "no se nace demonio, se hace uno demonio. Demonio es, pues, una manera de ser; ser-en-transfinitud transfinitante"'3.

\subsection{La transfinitud del En-ser (Da-sein)}

Hacia la milad de la década de los cuarenta, la influencia del existencialismo heideggeriano va ocupando el lugar primordial que hasta entonces venía ocupando el "raciovitalismo" orteguiano. En esta nueva etapa de su pensamiento, que va aproximadamente de 1947 a 1960 , la idea a cerca del hombre se inviste con las categorías ontológicas del filósofo alemán. Pero tras este nuevo ropaje, la concepción de fondo que tiene sobre el hombre apenas varía.

El ser humano, desde la óptica ontológica del "Da-sein", se nos aparece, según GB, como una realidad cuya existencia no se halla a la altura de su esencia, debido a que su realidad esencial se halla "proyectada", aherrojada y caída en la existencia fáctica. Por eso, el hombre se comprende a sí mismo como "ser-que-está" (En-ser, Da-sein).

"La ontología clásica, señala GB, supuso siempre que cada tipo de ente existe con una existencia adaptada justamente a su tipo de esencia, y así pudo establecer la unidad entre «<qué es»> o esencia, y su «<que es»>, existencia: entre ente y ser, entre el ser y lo-ser"14. Pero desde la óptica de la hermenéutica existencialista advertimos lo erróneo de tales planteamientos.

El error de la metafísica tradicional, de profundas consecuencias antropológicas, consistió, como acertadamente advirtió Heidegger en "Ser y Tiempo", en confundir el Ser con el ente (la sustancia). El Ser ya no es para Heidegger un ente concreto, sino un ámbito iluminado u horizonte donde todos los entes cobran sentido. De modo que el Ser "es dado atemática e inobjetivamente (unthematisch, ungegenständlich)"15. 
El hombre aparece, por ello, en el mundo de los entes, como un ente privilegiado, por un doble motivo: porque es el único ente que se hace problema por el Ser y por su ser (su propio ser es ser problema, advertirse como problema), es el único en quien aparece la pregunta por el sentido del Ser; y, en segundo lugar, porque su misma realidad se halla atravesada y complicada por la doble cara con que está constituida la realidad ontológica: el ente y el Ser. Y aquí sitúa ahora GB la condición dramática de lo humano, en paralelo a la condición transfinita de la etapa anterior.

Y ello es así por cuanto el ser humano encama en su realidad más esencial una doble tendencia: hacia Ser y hacia ente. Por su componente de Ser, se halla lanzado hacia lo indeterminado y sin fronteras, reflejando en ello su condición de absoluta maleabilidad, abierto a lo que sea y a lo que venga. En cambio, por lo que tiene de ente, se halla el hombre abocado y arrojado a ser una cosa más, uno de tantos entes concretos, encerrado en una naturaleza fija y estable. Estas dos caras se hallan reflejadas en su doble condición de ex-sistencia (capacidad de salir de sí para ser cualquier cosa) y de in-sistancia (arrojado al mundo, apegado a lo fáctico). Las dos dimensiones o facies de su realidad tienden a combatirse y anularse, y también a ocultarse muluamente. $Y$ en esta lucha radica precisamente la dimensión dramálica y trágica de la existencia humana. Pero de aquí también surge la doble posibilidad existencial de adscribirse a una "vida auténtica" (dominada por el impulso de la ex-sistencia) o a una vida "inauténtica" (empujada por la in-sistencia, la vulgaridad y el "cualquierismo").

Ahora bien, al igual que en la etapa anterior, la condición corpórea del hombre es factor esencial para situarse en uno u otro nivel de existencia. La persistente concepción dualista del hombre que posee GB, le hace entender lo corpóreo como algo secundario y subordinado a lo espiritual o psíquico. De ahí que señale que somos más ente en cuanto al cuerpo y más ser en cuanto al espíritu'th. Ambos, cuerpo y mente, están sujetos a la dinámica de transfinitud de todo lo humano, que abarca, según GB, cinco estadios etapas: uno-de-tantos o cualquiera, particular, individuo, singular y persona ${ }^{17}$. Desde su condición de uno-detantos, perdido en la masa y en lo impersonal, el hombre tiene que ir ascendiendo en un proceso de cristalización y solidificación de su interioridad hasta constituirse en persona, etapa en la que el ser humano deviene realidad única e irrepetible. Pero se trata de un estado o meta ideal a la que hay que apuntar, aun conscientes de que nunca se llegará a conseguirlo, porque nunca se puede estar siendo en estado puro de único, de persona. Y ello es así porque lo corpóreo aparece como estorbo o límite de finitud, que nos lastra y orienta hacia abajo la esencial tendencia del "trans" de nuestra estructura trans-finita.

Debido a ello, GB advierte que el hombre, si quiere conseguir y alcanzar su condición más auténtica, ha de atreverse a transformar incluso su propio cuerpo, para superar y debilitar las dificultades que lo corpóreo opone constantemente a 
nuestro empeño por elevamos al estadio de persona. Para ello, lo primero que tiene que superar el hombre es la idea equivocada de que el cuerpo posee una naturaleza intocable. GB lanza, a propósito de la transformación de lo corpóreo, y para convencer al hombre de sus propias posibilidades, una serie de ideas utópicas y provocativas sobre la posibilidad de alcanzar un cuerpo inmaterial, compuesto de luz y de ideas, que sirva de apoyo más adecuado al logro de la inmortalidad ${ }^{1 y}$.

Porque la mela de lo humano sigue siendo, para GB, "llegar a ser Dios en persona", o lo que es lo mismo, la consecución de la inmortalidad. Y precisamente en este punto, junto a otros, es donde se desmarca más claramente de Heidegger. Frente a la concepción heideggeriana del hombre como "ser-par-lamuerte" ("Sein-zum-Tode"), GB sitúa lo más auténtico y valioso del ser humano en su atrevimiento a ser inmortal, en no resignarse ante la muerte, y querer serlo todo, al estilo del Infinito, de Dios. Aquí precisamente se percibe un rasgo unamuniano que le acompañará siempre. El hombre no puede contentarse más que con la meta máxima: ser Dios en persona. Por intentarlo, repite obstinado GB, que no quede. En este empeño es donde se muestra de modo más palpable la condición que más le cuadra al ser humano: la de aventurero del ser, el atrevido, capaz de poner a loda la realidad, incluso a sí mismo, a ser o a no ser, por mediación de las virtualidades de la técnica".

\subsection{El humanismo térico, práctico y positivo}

En las décadas de los sesenta y setenta, GB construye y reorienta su sistema filosófico y su concepción del hombre desde el materialismo histórico de la filosofía marxista. El encuentro con el pensamiento de K. Marx le significó haber dado con las claves fundamentales de lo que va a conformar su sistema filosófico de plena madurez. $Y$ todo ello quedará plasmado, como un primer avance, en "Metafísica"zo), y completado y sistematizado después en "Curso sistemático de filosofía actual"2l y sus dos volúmenes de "Lecciones de Historia de la filosofia"z, por no hacer referencia más que a las obras mayores y más representativas de estos años.

Su concepción del hombre se reviste en eslos momentos de las calegorías del humanismo marxiano, y se plasma por primera vez en "Humanismo teórico, práctico y positivo, según Marx"23. El horizonte de comprensión de lo humano, aunque conserva los elementos más importantes e interesantes de las elapas anteriores, experimenta en este momento una transformación sustancial. La concepción del hombre es vista ahora desde el horizonte de la sociología crítica. La existencia humana ya no tiene sentido al margen del contexto social, que desde la óptica marxista es visto como una sociedad escindida en clases sociales y en permanente lucha de intereses encontrados. 
La condición "transfinita" del hombre se descubre y plasma ahora no tanto en las coordenadas individuales y existenciales, ámbito donde cada cual busca superar su propia condición fáctica hacia una meta infinita, que no pasa de ser un ideal abstracto que constituye una adecuación antropomórfica de la infinitud de Dios, sino que ahora esta dinámica transfinita se concreta y toma cuerpo en las categorías del materialismo histórico y dialéctico. La categoría clave de esta época, categoría cercana y sustitutora de "transfinitud", es la de "Iransustanciación"24.

Uno de los rasgos que, según hemos visto ya, caracteriza al ser humano es su capacidad de escapar a las constringentes condiciones fácticas de su realidad, esto es, su capacidad transformadora y transfinitadora de sí y de su mundo. Pero en la interacción práxica con el mundo se dan varios grados y niveles, entre los que GB distingue fundamentalmente tres: relación pasiva (contemplativa), transformadora y transustanciadora. Estos tres niveles reflejan y expresan otras tantas etapas a través de las cuales el ser humano se ha ido comprendiendo a sí mismo y se las ha visto con su entomo. Igualmente, estos tres niveles le sirven a GB para ordenar las etapas de maduración por las que han ido transcurriendo la historia de la filosofía, la ciencia, la técnica, la historia y el hombre mismo ${ }^{25}$.

Durante la época griega y medieval, el hombre se ha limitado a contemplar el universo, considerándolo, y considerándose a sí mismo, constituido por una naturaleza inmutable e intocable. De ahí que el ser humano se haya limitado a decir el logos, el ser, de las cosas. El hombre no ha pasado de hacer de altavoz de las cosas, mera operación onto-lógica.

Tras el Renacimiento, y sobre todo desde Kant, el hombre ha ido superando la actitud pasiva y contemplativa, haciéndosele patente la dimensión radicalmente activa del conocer. El hombre descubre que no se limita, en su relación con el mundo, a ser contemplativo, sino a construirlo, a transformarlo y a ir haciéndolo a su medida.

Pero nos hallamos actualmente en los umbrales de una época nueva, en la que el hombre ya no se está limitando a tranformar su mundo, sino que se siente capaz en cierta medida de transustanciarlo, tanto al mundo como a su propia realidad. Y "transustanciar" implica no la mera operación de cambiar de forma, sino de cambiar de sustancia las realidades mundanas. Y ello tanto en el ámbito de las realidades físicas (a través del paso de materia en energía, y viceversa, según la teoría de la relatividad), como también en el social (transustanciación de sistemas sociales), en el antropológico (ingeniería genética, cambios de estados de ser hombre), al igual que en cualquier ámbito de realidad.

La capacidad que el hombre actua $^{\text {th }}$ ha descubierto de transustanciar cualquier elemento de la realidad, la está ejercitando en una doble dirección: en la relación hombre-naturaleza, y en la relación hombre-hombre. Veamos cada una de las dos. 
(1) En la relación con la naturaleza, el ser humano experimenta un salto cualitativo y dialéctico en el paso que da de ser mera creatura (y "por-diosero") a encontrarse siendo creador; de subordinado a la naturaleza, a Señor y creador de ella. En esta relación dialéctica hombre-naturaleza es donde se produce simultáneamente la humanización de la naturaleza (transustanciada en mundo, hecho por el hombre y para el hombre), y la aparición o emergencia de la auténtica naturaleza del hombre (su condición de creador y transustanciador).

Pero antes de descubrirse y constiluirse en creador, el hombre ha tenido que ir subiendo varios peldaños de hominización, a través de los cuales se ha ido haciendo no sólo distinto (por naturaleza) de los animales, sino diverso (por autotransformación). Los estadios que ha tenido que superar los denomina GB hombre primitivo, hombre primero (o primer hombre) y hombre primario o propiamente hombre. Este último estadio queda definido como "aquel que inventa la manera de no ser creatura de nada ni de nadie, muestra con obras, con práctica, que se ha hecho diverso de todo, inclusive de eso suyo, previo inmediato: ser Señor de lo-natural. Se ha hecho, pues, a sí mismo Creador, ya que creador, a diferencia de Señor, no sólo es distinto de sus productos, sino diverso de ellos, tan diverso que los invierte y los hace inversos: resultan creaturas los comenzaron por ser creadores"27. Inversión, pues, de roles: se abaja la naturaleza y se eleva y reencuentra el hombre con su propia naturaleza.

(2) Pero la aparición del verdadero ser del hombre, su realidad de verdad, se produce en el ámbito de las relaciones interhumanas, como culminación de un largo proceso humanizador. GB, siguiendo a K. Marx, denomina a las tres etapas que componen este proceso "humanismo teórico", "humanismo práctico" y "humanismo positivo"2s.

(a) El "humanismo teórico" se alcanza cuando el hombre consigue transustanciar la realidad de Dios (que no es más que pura proyección del ideal humano fuera de sî) en su propio provecho. El ser humano descubre, por tanto, en esta primera etapa, su condición de "por-diosero" y la necesidad consecuente de reganar para sí lo que ingenuamente había proyectado en Dios. Esta fue la labor de L. Feuerbach, conlinuada por K. Marx. Ahora bien, este estadio de humanización, aunque necesario, es insuficiente, porque sólo sirve para alcanzar la humanización pero de forma meramente teórica. Se necesita apuntalar esta conquista desde la dimensión práctica.

(b) La fase del "humanismo práctico" tiene por objetivo la transformación de la realidad social, a través de la transustanciación de la propiedad privada (etapa de "comunismo"), de modo que se hagan desaparecer las condiciones de posibilidad de la alienación del hombre, tanto en su dimensión económica, como también religiosa (fase anterior), en la medida en que la religión funciona, según el marxismo, como superestructura ideológica del capitalismo. 
Este proceso de consecución del "humanismo práctico" conlleva en su seno unos ingredientes de enorme trascendencia para la auténtica comprensión de la antropología y sociología de GB. El paso del "humanismo teórico" al "práctico" significa o supone un doble salto "iransustanciador": $(i)$ desde un mundo artificioso (desviación capitalista del mundo artificial), en el que los productos del trabajo sirven sólo para unos pocos (los capitalistas), hasta la sociedad comunista, como designio de "mantener la objetividad de los productos humanos, eliminando su enajenación"z"; (ii) y desde un hombre escindido en dos bloques, trabajadores y capitalistas, y alienado (al estar despojado del producto de su trabajo) ${ }^{30}$, hasta la sociedad total, que reunirá a la totalidad de los humanos, tras haber atravesado las fases previas de colectivo, grupo individual y la meta definitiva: la Sociedad, definida por GB como "comunidad de personas, expuesta a universo, patente en mundo, según un plan de vida total, presente y actuante en cada una de ellas por modo de Ideal"'s! .

El hombre creador, trabajador, transustanciador, por el propio efecto de su trabajo, es constitutivamente social, superando, a través de sus creaciones, su condición de individuo aislado. De ahí que el individualismo de la sociedad capitalista es fruto de la escisión artificial del ser humano, consecuencia del plan y designio del capital. ¿Y en qué consiste esta escisión artificial? Veámoslo. El hombre creador, en la medida en que lo es, todo lo que crea lo hace para que sirva "para cualquiera". Esto es, en la misma esencia de su acción creadora se halla inscrita la socialidad de su condición humana.

De ahí que diga GB que el proyecto humano de Sociedad, en el que no se darán ya trabas para que el hombre viva su auténtica condición social, funciona como ideal provocativo de la situación actual. El hombre, por tanto, es social por naturaleza, aunque puede vivir, $y$ de hecho vive, escindido por el proyecto $y$ designio exitoso que constituye y se llama "capitalismo".

Cuando el capitalismo imperante en la actualidad haya sido transustanciado en comunismo, será el momento en que transparecerá la auténtica condición humana, su condición de creador y de hombre social.

(c) Pero cuando esto llegue a ser realidad, si alguna vez llega a serlo, todavía no habremos alumbrado el fin de la historia, sino que solamente habremos puesto los cimientos del "humanismo positivo". El "Humanismo práctico" es condición necesaria, pero no suficiente, para la última fase o etapa de humanización. Nos hallamos, con todo, abocados a la tercera y definitiva fase de este proceso humanizador.

Ahora bien, sobre esa etapa no podemos hacer grandes afirmaciones premonitorias, sino leves atisbos, entremezcla de sueños y deseos anticipadores, aunque apoyados de realidades sintomáticas del momento presente. 
El "humanismo positivo", nos dice GB, es "el porvenir de la humanidad"32. No simplemente el futuro. El futuro es una categoría de la historia natural: adviene ateniéndose a las leyes naturales. El porvenir, en cambio, hay que crearlo; pertenece a la "historia artificial", creada por el hombre y para que sirva al hombre. Como tal "porvenir", carece de racionalidad "prospectiva". Sólo posee racionalidad "retrospectiva", discernible sólo a posteriori. Esto es, surge simplemente "porque si"; le adviene al hombre como ocurrencia e invento, aunque necesita, como condición encesaria poner condiciones previas que hagan surgir tales ocurrencias como chispazos de creatividad.

Pero aunque el "humanismo positivo" rechaza, por imposibilidad intrínseca, la definición de su contenido específico, sí pueden señalarse algunos ingredienles de su estructura formal interna. GB señala dos:

(a) La transustanciación de la historia, esto es, su transustanciación de natural en sobrenatural o artificial. En la historia artificial, el tiempo natural (cuyas tres dimensiones son pasado, presente y futuro) queda transustanciado en y constituido por un tiempo también artificial, cuyas dimensiones son pretérito, presencia y porvenir ${ }^{33}$. En la historia natural, los sucesos acontecen pasivamente. En la artificial, los acontecimientos serán tal y como el hombre decida que sean. Ya no sucederán las cosas porque sí, sino que habrá conseguido dominar totalmente los acontecimientos históricos; habrá inventado "la manera de que todo haga ante él y para él acto de presencia"”* .

(b) Y la instauración de la libertad del hombre sobre el reino de la necesidad. Eslo no es posible más que cuando el hombre credor se decida y consiga transustanciar completamente el mundo natural en mundo artificial o tecnocosmos: mundo sometido a una necesidad sobrenatural. Sobre un mundo sometido al imperio de leyes nuevas, artificiales, es posible instaurar el reino de la libertad humana, donde pueda realizar sus nuevos planes sin ninguna cortapisa.

La imposición del orden nuevo, sometible al dominio de la libertad, se tiene que imponer tanto en el ámbito de la naturaleza material, como en el propio ámbito de la libertad humana. En el ámbito de la naturaleza, el hombre tiene que implantar mediante la técnica un mundo de "artefactos", en cada uno de los cuales haya separado y distinguido fuerza y dirección, esto es, la "función motora" y la "directora o vectorial".

Pero también en el reino de la libertad caben polenciaciones y elevaciones de estado: del estado de libertad nalural (reino de "lo que me da la gana") al de libertad social, consistente en transformar las "ganas" espontáneas individuales en una empresa común, en la que todas las libertades colaboren y se aúnen.3. Esta confluencia de libertades individuales, bien encauzadas de cara a un proyecto común, dará paso y será base de la libertad sobrenatural, artificial y transustanciada ${ }^{36}$. 
La concepción antropológica de esta época marxista posee una riqueza tal de contenidos, que no pueden ser aquí explicitados ${ }^{37}$. Pero sí hay que señalar de forma conclusiva algunos aspectos, con ánimo de retomarlos más adelante en las conclusiones finales, o en la segunda parte de este trabajo. La concepción del hombre presente en esta etapa ha tomado profundidad, concreción y una dimensión sociocrítica que carecía en los años anteriores. El hombre es visto ahora en función, o desde la óptica de su dimensión social. Pero no se trata de una socialidad idológicamente neutra, sino en la línea de la lucha de clases del marxismo.

Ahora bien, con el cambio de óplica no ha dejado de lado, sino que la ha mantenido trascendiéndola, si idea del hombre "Iransfinito". Sólo que ahora la transfinitud se ha potenciado (aunque también hay que señalar que el conceplo "Iransfinito" no aparece casi en los escritos de esios años). La utopía del humanismo "garciabaquiano" considera el objetivo de llegar a ser Dios, o la transustanciación de Dios en provecho del hombre verdadero, no como la meta definitiva del proceso humanizador, sino como uno de sus peldaños previos que tendrá que completarse con otros dos posteriores: el humanismo práclico, como implantación del comunismo, y el humanismo positivo, meta final de la historia.

Ahora bien, si Dios, en su contenido tradicional y explícito, no constituye ya la mela de la realización humana, la idea de Dios, sin embargo, en lo que implica de absolutez, infinitud, omnipotencia, etc, aparece configurando y constituyendo la ulopía de la sociedad futura del "humanismo positivo". El hombre social (como dice GB, "Nos", "Sociedad") posee en las descripciones que utiliza GB tales connotaciones divinas (inmortalidad, infinitud, omnisapiencia, omnipotencia, omnipresencia,...), que resulta evidente que Dios, como idea reguladora, sigue siendo considerada, también ahora, como la meta de la humanidad. Por tanto, ser Dios en persona, aunque ahora ya no como proyecto de cada individuo sino del todo social, continúa siendo el punto de referencia de la dialéctica existencial humana.

\subsection{La utopía del "homo technicus"}

Pero el pensamiento de GB no se agota con la época manxista, aunque ésta constituya el momento cumbre de su madurez filosófica y en la que publica sus trabajos más logrados. Durante la década de los ochenta, su pensamiento se ha ido distanciando paulatinamente del talante crítico-social del marxismo. Y aunque no lo abandona del todo, encamina su filosofar hacia otros derroteros, recuperando de nuevo acentos y temas pretéritos. En concreto, su idea de la "transfinitud". Las dos nolas claves de esla etapa postrera de su pensamiento considero que son el progresivo distanciamiento del marxismo, y el papel central que va cobrando la reflexión sobre la materia, desde la óptica científico-técnica. 
Si en la etapa anterior, toda la concepción creadora y transustanciadora del hombre, dirigida sobre la realidad natural y sobre sí mismo, se veían siempre desde un planteamiento crítico, advirtiendo el desvío "artificioso" que los intereses capitalistas han introducido en el mundo "artificial", fruto de la acción creadora del trabajador, quedando escindido, rebajado y alienado al hombre "creador", en las obras más recientes, estos acentos se hallan paulatinamente ausentes. GB contempla y describe el proceso creador del hombre como un ejercicio libre de cualquier desvío alienante. El "mundo artificioso" parece que ha dejado de existir, y ya no ejerce ningún influjo esclavizador sobre el trabajo creador del hombre. Todo el trabajo creador que el hombre realiza se sitúa, sin más, en lo que antes denominaba "mundo artificial".

La ciencia y la técnica siempre han tenido un papel central y preponderante en el pensamiento de nuestro filósofo, pero nunca como en estos últimos años. De tal modo que, según GB, el trabajo científico, con su concreción llevada a cabo a través de la técnica, están desbancando a la filosofía del rol fundamental que hasta ahora desempeñaba, en cuanto ontología y metafísica. Según ello, al saber científico no le corresponde ya un mero papel secundario, como ayudante de la ontología. Más bien se han intercambiado los papeles: la ontología (filosofia contemplativa) no alcanza más que a mostramos el nivel "aparencial" de la realidad, lo que están siendo las cosas ante nuestros sentidos macroscópicos. En cambio, el papel que hasta ahora correspondía a la ontología (decir qué son las cosas, descubrir su realidad de verdad) y a la metafísica ("transustanciar" la realidad) lo está ocupando con más mérito y éxito el saber científico-técnico, puesto que sólo él nos está descubriendo la realidad-de-verdad de lo que hay, la "micro-realidad", como fundamento de la "macro-realidad", nivel éste de mero "aparencial" e insuficiente en el que hasta ahora se había movido el saber humano ${ }^{36}$. La ciencia actual nos está desentrañando la base radial del ser de toda la realidad.

De ahí que la ontología, la antropología, la teología incluso, y cualquier otro ámbilo del saber teórico, se convierten, desde esta nueva perspectiva, en radioontología, radio-anıropología, radio-teología,... Su nueva concepción antropológica se halla impregnando, como siempre, todos sus últimos escritos, pero se concentra de un modo especial en "Tres ejercicios literario-filosóficos de Antropología" "Qué es Dios y quién es Dios", "Vida, muerte e inmortalidad", "Transfinitud e inmortalidad"us) e "Infinito, transfinito, Finito"41.

El hombre actual, según lo ve GB, está siendo y cumpliendo la función de espoleta del universo, tras haber superado dos etapas inferiores: la de altavoz (mero decir y vocear el ser de las cosas) y prisma (descomponer y transformar la realidad, sin llegar a transustanciarla). Y ello se debe a su condición de poseedor de una ciencia y técnica en fase de transustanciación, con las que está ya trastomando parcialmente la propia naturaleza de las cosas, en espera de llegar a 
proponerse un plan completo de transuslanciar total y definitivamente la naturaleza de su mundo.

El propio hombre se presenta ante sí como material explotable, es decir, "explosión aprovechable para subvenir de manera nueva a necesidades (finalidades naturales) o para satisfacer necesidades inventadas (o metas extranaturales) o para meterse en empresas, es decir: para proponerse proyeclos, designios o tomar decisiones cuyo resultado incluya un marco de éxito y un no eliminable margen de aventura (riesgo) y, por ello, de fracaso"'az.

El ser humano se ha puesto a trasustanciar su propia realidad, o al menos a intentarlo, desde el nivel de lo biológico-genético hasta el socio-político y éticoreligioso. Y en ello está mostrando, una vez más, según GB, su condición y talante de atrevido y aventurero ${ }^{43}$. $Y$ en tal aventura no tiene seguridad de éxito, pues sus ensayos pueden servir tanto para el aprovechamiento de la energía que saque de ellos como una ocasión para destruir toda la realidad y a sí mismo con ella. Más, a pesar de ello, su condición de "atrevido" le empuja permanentemente a "no dejar títere con cabeza", en castiza expresión de GB.

La condición transfinita de lo humano aparece de nuevo en esta etapa final, incluso en los títulos de varios de sus textos ("Transfinitud e inmortalidad", "Infinito, transfinito, finito"), dentro de lo que he denominado el eclipse de la época marxista. Esta condición transfinita la experimenta el hombre en la incapacidad que muestra de someterse a las encerronas y emboscadas que le tiende permanentemente la realidad, queriéndole encerrar dentro de sus estructuras. Pero él está mostrando que saber siempre "salirse de todas". Su poder "transfinitador", ejercilado y mostrado a través sobre todo del saber científico-técnico, ha conseguido superar un cúmulo de "encerronas" de la naluraleza. A cada "encerrona" de la naturaleza, el transfinilo le sabe dar la vuelta, oponiendo una nueva transfinitud inventada. Tales encerronas y sus correspondientes superaciones graduales son tanto de naturaleza coporal y material, como de lipo intelectual y cultural ${ }^{\text {44 }}$.

Por lo que tiene de finito, el transfinito siempre necesitará de apoyaturas concretas para seguir existiendo, aunque tales apoyaturas serán provisionales y superables. Si no necesitara de tales límites, el hombre sería infinito y no meramente "trans-finito". Su propio cuerpo es el límite y la barrera más difícil, a la vez que necesaria y también superable. Pero cuando, nos dice GB, el hombre se atreva a meterse con su propio cuerpo, habrá iniciado la historia humana una nueva y trascendental era en la que podrá atisbarse la inmorialidad. Y éste es el sueño permanente de GB, como contrapeso del "ser-para-la-muerte" de la antropología existencialista, constituyendo un ingrediente medular de sus ansias utópicas de llegar a ser Dios en persona, meta del "transfinito". Si en la época manxista, la búsqueda de la inmortalidad, tanto individual como de la especie, aparecía sólo meramente apuntada, en esta etapa final se convierte en un tema 
obsesivo y explicilado sin ningún pudor. La meta del hombre está claro que para GB es llegar a ser inmortal. Pero ahora resulta que esos anhelos experimentan una reorientación curiosa, por cuanto es posible que ya no necesitẹmos esperar al más allá de la muerte para cumplir tales deseos. Es posible que ya estemos siendo, de alguna manera, en el momento presente, inmortales.

GB ha dedicado, en sus últimos años, dos libros (Vida, muerte e inmorsalidad y Transfinito e inmortalidad) para tratar, de modo explícito y concreto, esta su obsesión de muchos años atrás. Parecería como si con el paso de los años y con la cercanía de la muerte propia, se le avivara la pregunta por el destino y el momenlo final de la vida humana.

El nuevo enfoque que da ahora al problema está acorde con su concepción de la ontología científico-técnica. La experiencia ordinaria y superficial que tenemos de nuestra vida, no pasa de situarse en el nivel de la "macro-realidad" (mera apariencia de su realidad profunda). Pero la vida auténtica se halla en el nivel de lo "micro", el ámbito del qué es auténtico. Es en ese nivel donde nuestra vida está cósmicamente distendida y en comunión con todo el universo, como ámbito campal de todo lo que hay.

Según eso, la inmortalidad, o la vida auténtica, consistirá, según GB, en dejar de vivir en lo "macro" para pasar a vivir en lo "micro", provislos de un cuerpo cósmico, cuerpo de luz, En realidad, tenemos que decir que se trata de dos tipos de vida, que pueden considerarse sucesivas pero también simultáneas: vida en cuerpo (nivel macro) y vida en soma (nivel micro) ${ }^{45}$. Nuestro soma está, pues, constituido por las partículas elementales de la materia, y viene a ser equivalente, en la idea de GB, a un "cuerpo astral" o "nuclear".

En realidad, aunque nuestra conciencia y sensibilidad naturales $o$ ingenuas nos hacen vivir normalmente en lo macro, en el ámbito del cuerpo, estamos simultáneamente viviendo en el nivel micro, en el soma, aunque no seamos muy conscientes de ello. Por ello, de alguna manera, estamos siendo ya inmortales. Lo que ocurre es que, para que sea posible la vida en el ámbito de lo macro, ha de hallarse oculto y preterido lo micro, como su cimiento y condición de posibilidad. Sólo de vez en cuando, por golpes probabilísticos, emerge repentinamente la micro-realidad, haciéndonos entonces atisbar una dimensión nueva: lo imperecedero e incorruptible.

Según esto, GB nos muestra las diferentes elapas de la vida humana (etapa prenatal, niñez, juventud, madurez y vejez) como un lapso de tiempo (ranscurrido entre dos extremos de naturaleza idéntica: el estado nuclear. Nacer es emerger de lo micro hacia lo macro, y morir es simple "reversión" al estado nuclear $^{\text {th }}$. Podría decirse, por tanto, que la inmortalidad nos pertenece por naturale$z a$, puesto que siempre estamos compuestos por, y apoyados en la base micro, nuclear. Vida y muerte, vida e inmortalidad, son dos estados de la misma reali- 
dad. Unica realidad que es el conjunto del universo, comprendido por GB desde una óptica panteísta, tal y como lo describe en "Qué es Dios y quién es Dios".

\section{La apertúra permanente a lo "Irans"}

El recorrido que acabo de realizar nos muestra palpablemente tanto el talante proteico y moldeable del pensamiento garciabaquiano, como también su fundamental continuidad con un fondo original y propio que se manliene presente desde sus primeros escritos tras la guerra civil.

La imagen del hombre que palpita debajo de tal diversidad de ropajes se halla constituida por un conjunto de ingredientes que conforman lo más original de su concepción antropológica, revestida en cada época con categorías y conceptos diversos, según la influencia filosófica de turno. Paso a señalar a continuación cuáles serían esos rasgos específicos.

(a) El primer rasgo lo constiluye su radical antropocentrismo, en oposición dialéctica a cualquier concepción teocéntrica o heterónoma del cosmos y de la historia. GB parte de que "Dios ha muerto" y, por tanto, el hombre está solo y alenido a sí mismo. El hombre, como especie emergida y evolucionada a partir de la Naturaleza, es el único señor y dueño de su vida y de su mundo ${ }^{47}$. Pero esto no lo percibe el hombre espontáneamente. Ha de aprender a entenderse exclusivamente desde sí mismo y no desde cualquier otra instancia absoluta, que tenga el peligro de descentrarlo y situarlo en unos parámetros existenciales y éticos helerónomos.

Nacido, como indigente y "por-diosero", de la naturaleza, su propia experiencia le irá descubriendo su auténtica realidad y se irá aupando al único puesto que le corresponde: primero Señor y luego Creador de sí mismo (paso de hombre natural a hombre nuevo: creador y transustanciador) y de un mundo nuevo (el mundo artificial, el tecnocosmos), fruto de la "transustanciación" del mundo natural.

Esta concepción prometeica de la realidad humana propuesta por GB no queda satisfecha con aspirar simplemente a ser "imagen de Dios", vieja aspiración bíblica, sino con llegar a ser "Dios en persona". De ahí que el ser hombre implique, para GB, la encarnación del talante "demoníaco" del mito de Luzbel, rebelde contra Dios y contra todo tipo de barreras ontológicas y éticas impueslas desde la sumisión teística ${ }^{4}$.

Pero esto no implica sin más negar la existencia de la realidad de Dios, sino su transformación en meta utópica e idea reguladora hacia la que se debieran orientar todos los anhelos existenciales del hombre. El ser humano aparece, pues, definido en GB como "deseo de ser Dios", en cuanto tal deseo implica querer alcanzar "aquello más allá de lo cual nada puede ser pensado" (por acudir a la conocida definición anselmiana). Pero esa meta, ser Dios, GB la irá enten- 
diendo y plasmando de diferente modo en cada una de las etapas de su pensamiento, como hemos tenido hasta cierto punto ocasión de ver en las páginas anteriores.

(b) El segundo rasgo lo constituye la concepción dinámica y progresiva de la autoconstrucción del hombre. La idea de una naturaleza humana fija y encorsetadora de lo humano queda radicalmente arrumbada, para ser sustituida por la evidencia existencial de que ser hombre es no un regalo de la naturaleza, sino una tarea cuya realización, tanto constituya un éxito o un fracaso, depende exclusivamente de la libre decisión de uno mismo, en el doble sentido ya apuntado por Ortega y Gasset: en cuanto que no sólo tiene que hacerse (siendo cada uno agente de su propio destino y autorrealización), sino también en cuanto que tiene que elegir en qué dirección tiene que hacerse y realizarse (como autor de su propio drama). En este sentido, el hombre es en doble medida "causa sui"4y .

Para GB, repitiendo la idea de Bergson, el hombre no sólo elige sus posibilidades, sino que además tiene que crearlas. Es el creador e inventor de su propio camino, de sus no predeterminadas formas de ser, por hallarse dotado de una plasticidad casi infinita ${ }^{50}$.

(c) Tercer rasgo: una concepción procesual y estadal de la antropogénesis. Desde sus primeras obras, GB acostumbra a señalar y delimilar claramente las diferentes etapas por las que el ser humano ha de discurrir para llegar a ser hombre cumplido: en su primera etapa, nos habla de tres fases: singular, individuo y persona. En la segunda, las fases se amplían a cinco: uno-de-tanlos/cualquiera, particular, individuo, singular y persona. En la etapa marxista, las fases de antropogénesis se complejifican, en la medida en que nos presenta dos niveles de humanización: por un lado, en la dialéctica hombre-naturaleza, el ser humano ha de atravesar las fases de hombre natural, hombre primero y hombre primario; y por el otro, desde la dialéctica de las relaciones interhumanas, las tres fases que tiene que alravesar el proceso antropogenésico son "humanismo teórico", "humanismo práctico" y "humanismo positivo". Y en la última etapa, el proceso de hacerse hombre atraviesa las fases de altavoz, prisma y espoleta de sí y del universo.

Sea cual sea la denominación y el contenido que en cada etapa de su pensamiento da a las diversas fases de este proceso humanizador, en todas ellas aparece la condición humana como un proceso dialéctico ascensional que parte de un nivel inferior cosificante, "nadificante" o inauténtico, para apuntar e intentar llegar a una meta utópica, que se considera como la "vida auténtica", en la que el hombre viva su existencia a la altura de su condición más verdadera, desentrañando lo que en realidad de verdad se halla contenido en la esencia de lo humano, tanto en su dimensión individual como social.

(d) El cuarto rasgo se concreta en el carácter tensional y dramático de la existencia humana. La concepción procesual y estadal de la condición humana 
conlleva al mismo tiempo una visión tensional de la existencia, no exenta de dramatismo (aunque no llegue a lo trágico). La realización humana es fruto de la tensión entre dos fuerzas que tiran de él en direcciones opuestas, con evidente peligro de descoyuntarlo: la que lo arroja hacia las cosas, la nada y lo inauténtico (con peligro de ser un "don nadie", "uno-de-tantos", en situación de "cualquierismo" y "ninguneo"), y la que tira de él hacia su condición más elevada, como meta que atisba e intuye, aunque no sabe con exactitud en qué consiste. Entre otras razones, porque no hay nada prefijado de antemano que le muestre en qué consiste ser hombre. El es el único autor y actor del drama de su vida. Pero, además, hay dos aspectos más en que se basa este dramatismo y tensionalidad, referidos ambos a la meta última de su existencia. Uno de ellos se refiere al hecho de que la meta ideal de la autorrealización humana consiste en ser "yo", o lo que es lo mismo, en ser persona, como realidad única, y en estado de único. Pero, en la medida en que somos realidad en-materializada, y estamos encorporeizados, el anhelo de ser únicos se muestra de imposible realización. Porque tener y ser cuerpo, y consistir nuestra condición en ser-en-el-mundo, implica estar siempre lastrados por un componente de "cualquierismo" que rebaja y tira de nuestro ser hacia la condición de cosa. De ahí que el destino irrevocable de la existencia sea perseguir una meta que en su idealidad pura se nos aparece como imposible: ser yo, único, persona, teniendo que vivir a la vez en cuerpo material.

De nuevo se nos aparece la dual condición del "trans-finito": superar barreras, pero sin llegar nunca a conseguirlo del todo, pues siempre necesitará de alguna para poder ser y seguir existiendo.

El otro factor de tirantez dramática se muestra en la supuesta tendencia del hombre a ser Dios, constituyendo este empeño una meta radicalmente imposible. La existencia se nos presenta igualmente, desde este punto de vista, como un apuntar a un objetivo sin llegar a dar nunca en el blancos. Dios es la meta a la que apuntar, pero sabiendo de antemano que es un meta en sí misma imposible.

Ahora bien, a pesar de esta dimensión tensional, y hasta cierto punto dramática, de la existencia, nunca se dan en GB los acenlos trágicos que caracterizan, por ejemplo, al existencialismo santreano. La vida se aparece ante GB como un drama pero no como tragedias2. GB nunca ve al hombre como una "pasión inútil", sino como un arco tensado hacia un blanco alisbado, aunque nunca definido. Hay en ello también una cierta sintonía con la visión deportiva y aventurera que se halla presente en la antropología de Ortega y Gassel, y que sin duda ha dejado su influencia en $\mathbf{G B}^{53}$.

(e) Un nuevo rasgo es la dialéctica del hombre con la naturaleza, como escenario de la realización del hombre. Si el hombre está solo, tanto en su existencia como en la antropogénesis, el escenario en donde se realiza este proceso es siempre la Naturaleza. Al igual que K. Manx, GB entiende la realización 
auténtica del ser humano como fruto y consecuencia de la transformación y "transustanciación" de la naturaleza, por mediación del trabajo y de la técnica"st.

Esle diálogo con la naturaleza contiene en $\mathrm{GB}$, además, otros ingredientes especílicos y originales. Surgido el hombre de la madre Naturaleza, fuente de todos los recursos, la primera fase del diálogo con ella discurre en siluación de dependencia y desvalimiento frente a ella. La Naturaleza aparece como la fuerza todopoderosa y temible, y el hombre se percibe como su siervo, un "por-diosero". Es la primera fase de la realización humana, la del "hombre natural".

Pero el hombre no tardará en aprender a distanciarse de lo natural, sirviéndose de la naturaleza para sus propios intereses, adviniendo de este modo a su condición de Señor frente a su antigua dueña. Pero sólo cuando aprenda a transformar y transustanciar la naturaleza y conseguir que pase de su estado de "fisiocosmos" al de "tecnocosmos", habrá logrado que emerja en él su auténtica naturaleza: ser Creador de sí y de su mundo, ya no natural (compuesto por "naturifactos"), sino artificial/sobrenatural (integrado por "artefactos").

(f) El trabajo científico-técnico, mediación de la antropogénesis, constituye otro de los rasgos más significalivos de su pensamiento antropológico. En el diálogo con la naturaleza, la técnica ocupa un papel primordial e insustituible. El hombre, a lo largo de sus muchos años de historia, ha ido pasando de una relación pasiva con la naturaleza (fase contemplativa, ontológica o fenomenológica), en la que no se atrevía más que a ver y decir el ser de las cosas (función de altavoz), a una postura más activa y atrevida: transformarla, a través del trabajo técnico.

Pero el trabajo del hombre también puede tener diversos estados o niveles, a medida que perfeccione su capacidad de incidir transformadoramente en su entomo natural. Cada salto cualitativo en el ser de la técnica presupone y origina un nuevo salto cualitativo en el ser del hombre. Cada tipo de hombre maneja un tipo concreto de técnica, y cada tipo de técnica alumbra un tipo de hombre ${ }^{55}$. Podemos, por tanto, decir que en GB el hombre es tanto creador como creatura de la actividad técnica. La técnica es la obra del hombre (es capaz de pasar de "ojos a mano"), pero, a su vez, la técnica es la creadora del hombre ("homo technicus"), lo construye y lo moldea a través de sucesivos saltos de tecnicidad (paso de técnica contemplativa: altavoz, a técnica transformadora: prisma, y a técnica transustanciadora: espoleta) $)^{\text {sh }}$.

(g) La dimensión crítico-social de la condición humana. No le ha faltado a la visión del hombre en GB la dimensión interpersonal desde sus primeras obras. Pero sólo adquiere su obra tintes socio-críticos con la influencia marxista.

En las etapas anteriores, bajo el horizonte raciovitalista y existencialista, la definición que da del hombre, siguiendo a Ortega, es "capacidad de soledad", de llegar a ser yo como ser único. Desde esta forma de ver las cosas, el proceso de 
autorrealización del hombre se realiza y expresa casi exclusivamente en la interioridad de cada individuo, quedando lo otro, sean personas o mundo, como realidades al margen, mero escenario del proceso humanizador.

Su visión de lo humano cambiará rotundamente a partir del inПujo del marxismo, al que llega a través de la inlluencia de la pasión por el Pueblo que recibe de Antonio Machados7. El hombre no es nada al margen del contexio social, crílicamente interpretado desde la óptica del materialismo dialéctico.

Ahora bien, quisiera resaltar aquí, en relación con esta vertiente social de lo humano, un elemento original de la antropología de GB. Se trata de sus esfuerzos por fundamentar la dimensión interpersonal y social de la condición humana desde su condición creadora y transustanciadora. El hombre "creador" es el constructor de "artefactos" o "manufactos". Tales obras de su poder creador se le cosifican (constituyen auténticas realidades independientes de él) y se le alienan (no son para él, sino para el capitalista). De modo que, por efecto del plan deshumanizador del capitalismo, lo que está hecho para todos, para que sirva a todos y a cualquiera, se sustrae al uso y beneficio de uno, el capitalista.

De ahí que la perversión del capitalismo no es, desde la visión de GB, meramente ética y sociológica, sino que posee sobre todo una dimensión antropológica y ontológica. Y ello es así por cuanlo el trabajo creador no se orienta ni sirve exclusivamente al individuo que ha consiruido el artefacto. El trabajo es realizado por el trabajador en su calidad de uno-de-tantos y para que sirva a cualquiera. De ahí que la pretensión del capilalista de convertir el fruto del trabajo creador, que por naturaleza es para todos y para cualquiera, en algo para $m l$, el capitalista, representa ư atentado ontológico y antropológico; esto es, contra la naturaleza de la cosa trabajada, el artefacto, y contra el ser del trabajador. El capitalismo prostituye el carácter radicalmente social del trabajo humano.

Por tanto, para GB, el trabajo creador posee una radical respectividad (por emplear la categoría zubiriana) a todos los componentes de la especie humana, como potenciales usufructuarios del trabajo de cualquier creador. El "artefacto" es, por tanto, una de las mediaciones de interpersonalización y de socialización dentro del pensamiento antropológico de nuestro filósofo.

Por ello, es logico que GB señale que la propiedad privada es un atentado ontológico y antropológico, sólo posibilitado por y sustentado sobre una base jurídica interesada, construida por y al servicio de intereses capitalistas ${ }^{\text {ss }}$. De ahí que el ser humano llegará a su auténtica condición, la socjal, cuando transustancie la sociedad capitalista ("mundo artificioso") por medio de un acto revolucionario, y construya sin estorbos el "mundo artificial", única estructura social que permite el desarrollo espontáneo del verdadero hombre en la doble relación hombre-naturaleza y hombre-hombre. Sólo así podrá apuntar a la estricta utopía socialista: la conformación de Nos, Sociedad ${ }^{39}$. 
(h) El ansia de inmortalidad es igualmente una de las constantes de su concepción antropológica, tema recurrente desde casi sus primeros escritos. Si en sus dos primeras etapas, como ya hemos señalado en parte, la consecución de la inmortalidad era un ingrediente necesario y lógico dentro del empeño de llegar a ser Dios en persona; y en la etapa marxista, la inmortalidad se convertía más en propiedad del colectivo y de la especie humana que de cada individuo, aunque también de él, como ingrediente necesario para la configuración de la utópica sociedad futura ("humanismo positivo"), en la elapa más reciente, la inmortalidad se convierte en una realidad posibilitada por la tecno-ciencia en estado de actual ("transustanciadora"), e incluso aparece en estado o dimensión (en "microrealidad") ya presente en nuestra vida. Somos de alguna manera ya inmortales, en la medida en que participamos de la condición necesaria e infinita (en lo espacial y temporal) de la realidad del universo. El todo de lo que hay está adornado y constituido por rasgos específicos de lo divino, que van emergiendo a la macro-realidad como chispazos esporádicos de divinidad, aunque sólo de vez en cuando y sin ninguna razón suficiente, "porque sí" (atenido a las leyes de la probabilidad), a través de actos de creación y de genialidad de ciertos hombres. Por medio de tales actos de creatividad e inspiración están mostrando su condición de divinos, y la realidad deja reflotar su condición divina ${ }^{(n)}$.

(i) Dios, como meta permanente y obsesiva de la aventura humana, consituye también uno de los rasgos fundamentales de su idea del hombre. A pesar de que el hombre auténtico, según GB, tiene que desmarcarse de la tutela de Dios, dejando de ser un "por-diosero", su estruclura esencial está construida como permanente referencia al logro de ser Dios. Pero hay que señalar que el hombre no es nunca entendido en función y desde la óptica de Dios (en el sentido del Dios de las religiones, y sobre todo del cristianismo), sino más bien al revés: Dios es siempre visto y considerado desde lo humano y para lo humano. Se convierte así en la meta a la que hay que apuntar permanentemente, aun sabiendo que es imposible alcanzarla.

GB ha ido pasando en este punto de entender al hombre, en sus primeros escritos, como un "luchador con Dios" (al estilo de Jacob con el Angel de Yahvé) ${ }^{n+1}$, a hacer de Dios el ámbito formal de las aspiraciones fáusticas del hombre; aspiraciones a serlo todo, al estilo de Unamuno, sin dejar de ser uno mismo, con su yo y su mismidad.

Pero estas aspiraciones fáusticas de absolutez se revestirán de diferentes envolturas leóricas, según los años. Si en la fase historicista-vitalista la aspiración a ser Dios se entendía como meta de cada individuo, según ya quedó dicho más adelante, solapándose con el deseo de ser único y de llegar a ser yo, en la etapa marxista, la utopía divinizadora abarca la especie entera. Ser Dios equivaldrá entonces a encamar la etapa de "humanismo positivo", momento en que tratará el Hombre (en cuanto colectivo de la totalidad social) de encamar los rasgos que 
adoman lo divino: omnipotencia, omnisapiencia, bondad y justicia absolutas, invariancia e inmortalidad.

Ahora bien, en los escritos de sus últimos años, y especialmente en "Qué es Dios y quién es Dios" ${ }^{\prime \prime 2}$, ha desarrollado de forma más explícita, y en coordenadas un tanto distintas a lo defendido en etapas anteriores, su pensamiento acerca de Dios. Dios no es visto aquí tanto, aunque también, la meta de la realizacion del hombre, cuanto el ámbilo abarcador en el que el hombre se halla existiendo, $\mathrm{e}$ incluso, de alguna manera, ya siendo.

La concepción "radio-teológica" desplegada aquí por GB se halla enmarcada dentro de un "panteísmo" sui géneris (que denomina a veces "estadal"), por el que entiende que todo es Dios, aunque no cualquier realidad del mundo lo está siendo de la misma manera y al mismo nivel. Si todo es divino, sólo el hombre lo está siendo de modo especial y con conciencia de ello. Pero lo está siendo sólo a ratos, a chispazos, cuando emerge espontánea y programadamente su carácter creador.

Dios es, por tanto, el fondo inconmovible de toda la realidad existente, de cuyo fondo ha emergido todo, siendo el hombre una parte de tal todo. Pero es el hombre el único que se descubre encarnando la divinidad como un quién, como ser consciente en cuyas manos se halla el destino de todo, sabiendo que su destino depende también de ese todo, en la medida en que no es nada al margen de él.

Vemos, por tanto, que Dios no desaparece nunca del marco de reflexión que sobre el hombre y la realidad va construyendo sucesivamente GB. Dios y el hombre constiluyen, junto con la naturaleza, la técnica y la sociedad, los pilares siempre recurridos, aunque su conjugación estruclural difiera según las épocas.

\section{En las postrimerías de la modernidad}

El pensamiento filośfico de GB, a tenor de todo lo que hemos ido viendo, podríamos considerarlo como representativo de lo que podríamos denominar la modernidad tardia. Es decir, su filosofía viene a representar como una "reliquia" de la "tardo-modernidad" o de una cierta "modemidad tardía".

Sus postulados más originales se apoyan en, o parten de la visión postmetafísica y posteológica que se inicia con Fr. Nietzsche, y que sitúan al filósofo ante la necesidad de desmarcarse de una concepción antropológica encorsetada en calegorías ya marcadas de antemano por la cosmovisión teológica cristiana y por la melafísica greco-medieval, para orientarse hacia la búsqueda de unas nuevas categorías y valores que sirvan para construir un hombre y un mundo nuevos. La proclamación de la "muerte de Dios", como afirmación no ślo religiosa sino también, y sobre todo, metafísica, sitúa al ser humano ante la constatación de que ya no sirven los valores de la cosmovisión tradicional para 
seguir fundamentando nuestra existencia. Por tanto, hemos de abandonar la falsa pretensión de que exista un fundamento (Grund) en el que seguir sustentando nuestro mundo.

Pero los nuevos valores sobre los que hay que asentar y orientar nuestra existencia, tienen que ser inventados por nosotros, porque el hombre está solo, atenido exclusivamente a sí mismo, sin nada ni nadie a qué acudir para que le oriente en su nueva trayectoria.

Ahora bien, junto a la herencia postmetafísica que se inicia con Nietzsche, hay también en GB otras dos herencias culturales que marcan profundamente todo su entramado intelectual: el humanismo marxista y la racionalidad tecnocientífica. Estas dos herencias teóricas actúan en algunos momentos de modo conjuntado, y en otros, por separado. La segunda de ellas está presente de forma continua, mientras que la primera, sólo durante veinte años (las décadas de los setenta y ochenta). La época marxista es una interesante síntesis de dos humanismos: el crítico-social marxista y la visión humanizadora que posee de la racionalidad tecno-científica. Desde la síntesis de ambos ingredientes, se hace una crítica a la sociedad occidental capitalista ("mundo artificioso") y se dibuja la utopía socialista de un "mundo artificial o sobrenatural", la "sociedad", en la que la especie humana habrá superado la servidumbre de la naturaleza y la alienación a la que le tiene sometido la insolidaria sociedad capitalista escindida en clases.

Esta síntesis se mantendrá durante veinte años. Pero la crisis del socialismo real ha tirado por la borda (es posible que no de modo definitivo) lo que quedaba de credibilidad de la filosolía marxista, y ha constituido uno de los ingredientes que ha puesto en crisis todo el pensamiento filosófico más valioso y progresista de Occidente. Esta crisis la venía experimentando GB desde finales de la década de los setenta. Por ello, se siente abocado a revisar sus presupuestos y a realizar un desmarque (no brusco ni traumático) de lo que hasta entonces había consistido uno de los pilares básicos de su síntesis filosófica de madurez. Lo curioso y extraño (al menos para mi) es la nueva dirección que tomó su pensamiento en la última década de su singladura intelectual.

En realidad, este cambio de rumbo ha sido una necesidad compartida por muchos pensadores. Todos estamos siendo testigos en los últimos años de que uno de los problemas y discusiones más ricas y profundas, a la vez que más candentes, que están ocupando a los pensadores más valiosos e incisivos de la actualidad es el ajuste de cuentas con la "modernidad", esto es, con la herencia de la Ilustración ${ }^{63}$. Y en esta profunda y difícil encrucijada a la que se ve sometida la razón histórica en la actualidad, las posturas que han ido apareciendo van desde el neoconservadurismo y la postmodemidad, partidarios ambos de liquidar definitivamente la herencia de la Ilustración, por considerarla obsoleta, aunque por diferentes e incluso opuestas razones, hasta los neo-ilustrados, como Habermas 
y Apel, entre otros, defensores críticos de la modemidad, basándose en que lo más valioso de ella tiene todavía palpitante vigencia y está todavía pendiente de ser llevada a la prácticatat.

El posicionamiento de GB en esta encrucijada de la razón ha sido muy distinto. Yo lo calificaría de una cierta huida hacia adelante, en la que se desmarca del pensamiento marxista, dejando con ello de lado su visión crítica de la sociedad capitalista y sus acusaciones de explotación y alienación del hombre creador, e igualmente su visión utópica de una sociedad futura, construida sobre los pilares de justicia y libertad, para basar su apuesta por la emancipación y realización de lo humano exclusivamente en la dinámica interna de la racionalidad tecno-científica.

Su pensamiento postrero no tiene, por tanto, nada que ver con la crítica neoconservadora a las ideologías progresistas de origen socialista, viendo en ellas la raíz de todos los males que achacan a la civilización presente, y proponiendo como remedio volver a recuperar los valores que, según ellos, han constituido los cimientos del primer capitalismo: la moral puritana, la ética del trabajo, la religión y la familia tradicional. Y tampoco coincide su postura con los pensadores postmodemos, desengañados de los grandes "metarrelatos" (Lyotard) propios de la filosofía tradicional ("pensamiento fuerte" y totalizador), para refugiarse en el fragmento, en el "pensamiento débil" (Vattimo). A pesar de que GB sigue anclado en la fe en el progreso, su fe en que el progreso vendrá de la mano de la ciencia y de la técnica lo distancia radicalmente también de los neo-ilustrados Apel y Habermas.

La propuesta de salida que propone GB (aunque no tematiza explícitamente este problema) a la crisis de la racionalidad contemporánea, está impregnada de sugerencias interesantes pero también de muchos puntos débiles y serias interrogantes. Toda su concepción filosófica está siempre motivada por la fe en la realización y emancipación del hombre, que ha de venir exclusivamente de la mano del desarrollo y aclualización de la racionalidad tecno-científica. Y en esta apuesta de GB por las potencialidades de la ciencia y la técnica, hay una continuidad y una novedad respecto a todo su pensamiento anterior. La continuidad consiste en seguir considerando a la tecno-ciencia como un factor mediador en el proceso de humanización, sin considerar importantes las crílicas ante sus riesgos y limitaciones. Y la novedad se halla en reducir la confianza en la emancipación del hombre a sólo las posibilidades de la ciencia y de la técnica, dejando de lado la crítica sobre la utilización negativa que de ella está haciendo el capital, crítica certera y aguda que el propio GB realizaba en sus escrilos de la época marxista.

Parece que en estos momentos finales GB creyera que la dinámica intrínseca de la racionalidad tecno-científica contiene ya de por sí todos los ingredientes necesarios y suficientes para superar las contradicciones existentes tanto en el 
ámbito de la relación del hombre con la naturaleza como en el de las relaciones interhumanas, a todos los niveles. Sólo, por tanto, dejando que la ciencia y la técnica saquen a relucir todas sus potencialidades cabe esperar de su mano el advenimiento del hombre nuevo y de la sociedad renovada.

Pero esta cosmovisión tecno-científica plantea serios interrogantes en múltiples frentes: epistemológico, antropológico, sociológico, ético y teológico. En la parcela epistemológica resulta muy problemática la delimitación que realiza enIre ciencia y filosofía a la hora de asignar a cada una el papel que les correspondería para dar cuenta de la realidad, en su nivel más profundo y auténtico. En lo antropológico, resulta problemática tanto su idea de siluar la meta de la auléntica realización del hombre en su anhelo de ser Dios en persona, como su teoría sobre la inmortalidad en el ámbito de la "micro-realidad" (no se ve cómo asegurar de ese modo la persistencia, y menos todavía la individual).

Similares interrogantes se nos presentan desde la óptica social, descargada su propuesta de futuro de todos los acentos acertadamente críticos de la etapa anterior, y limitada a proponer como porvenir un mundo tecnificado, el "tecnocosmos". Es como si todos los problemas sociales de desigualdad, injusticia, alienación hubieran desaparecido sin acertar a saber cómo y por qué. i $\mathrm{Ha}$ desaparecido ya el "mundo artificioso"? ¿El mero desarrollo del proceso tecnificador del mundo será suficiente para su desaparición? ${ }^{\text {os }}$. Desde el punto de vista ético, da la impresión que para GB los valores que marcan lo que es bueno o no, lo que humaniza al hombre o no, se reducen casi a dejar que el hombre exprese su capacidad transustanciadora, tanto en sí mismo como en la organización social y estructura de la realidad material. El máximo valor y criterio de progreso se reduce a poner todo en el estado de "Irans". La pregunta que queda es si es suficiente transuslanciar la realidad, sin hacerse problema de hacia dónde se orienta la potencia transustanciadora ${ }^{\text {as }}$.

Y, por úllimo, su concepción "radio-leológica", plasmada en su "panteísmo estadal" de "Qué es Dios y quién es Dios", nos aboca a los clásicos interrogantes que todo panteísmo lleva consigo; es decir, por qué llamar Dios a una realidad en sí misma problemálica e infundada.

En definitiva, la concepción antropológica que nos presenta GB a lo largo de su dilatada y apasionante singladura intelectual, se nos antoja impregnada de no pocos aciertos y de interesantes sugerencias, pero llena, al mismo tiempo, de profundos y no fácilmente eliminables interrogantes. En su haber hay que situar su apuesta nítida y entusiasta por la realización y emancipación del hombre, de un hombre dueño de sí y de su destino, y consciente de sus infinitas posibilidades, y abierto a un mundo futuro inexplorado y apasionante, desde su condición de señor y creador de inventos y novedades.

Pero no podemos pasar por alto también sus puntos más débiles y oscuros, presentes a lo largo de toda su rica producción escrita, pero especialmente en sus 
últimas obras. Es en ellas donde se explicita completamente su excesiva confianza en las potencialidades intrínsecas de la racionalidad tecno-científica, haciéndose insensible a los aspectos más problemáticos y críticos de la sociedad en la que vivimos, profundamente injusta e insolidaria, al igual que a las profundas reservas que la "racionalidad ecológica" está planteando al "progreso tecnológico", desde la constatación de los límites de las reservas naturales y de los desastres ecológicos que un uso desmedido y depredador de la tecno-ciencia está ocasionando en nuestro entomo ecológico.

Alguien, muy acertada y plásticamente, ha descrilo el paso de la época de inicios del presente siglo hasta sus postrimerías como el salto de "la ebriedad tecnológica a la sobriedad ecológica". Siguiendo estos parámetros, ¿no habrá que afimmar que GB se ha quedado prendado del primer talante, sin ser consciente de la conveniencia de hacer caso a las sugerencias y llamadas de atención que nos plantea el segundo?

\section{Notas}

1. Cfr. Beorlegui, C., "La filosotia del hombre en García Bacca", J.D., Bilbao, Universidad de Deusto (Tesis doctoral), 1983; "García Bacca. La audacia de un pensar", Bilbao, Universidad de Deusto, 1988; "El pensamiento de Juan David Garcia Bacca, un filosofo navarro desconocido", Príncipe de Viana (Pamplona), VI(1986), pp. 213-240; "La visión antropológica de J.D. García Bacca", Estudios Filosóficos (Valladolid), 35, No. 99, 1986, pp. 269-294.

2. García Bacca responde a las posibles críticas sobre sus varios cambios de orientación filosófica con estas significativas palabras: "Yo he ido cambiando porque nunca me he preocupado de ser consecuente conmigo mismo. Es decir, no me he preocupado de ser consecuente con lo que iba haciendo, sino que me he ocupado de una cosa que no es ni mejor ni peor que lo de consecuente: en vez de preocuparme de ser consecuente con la verdad, simplemente me he preocupado por la sinceridad, que es afín a la verdad", "Entrevista con D. Garcia Bacca", Resumen, Caracas, XXV, 1979, 54, pp. 52-63.

3. Cfr. "Autobiografía inteleclual de Juan David Garcia Bacca", en Anthropos, Boletín de Información y Documentación, 1982, No. 9(6), pp. 4-10.

4. Cfr. Introducción al filosofar, Tucumán, Universidad Nacional de Tucumán, 1939; Invitación a filosofar, México: El Colegio de México, 1940-42; Tipos históricos de filosofar fisico, Tucumán, Universidad Nacional de Tucumán, 1941.

5. Invitación a filosofar, p. 3.

6. Cfr. Invitación a filosofar, p. 11.

7. GB recoge la frase de Platón en el Banquete que dice: "Todo demoníaco es algo intermedio entre lo divino y lo morlal", e igualmente le inspira la idea de Niezsche sobre el ser humano: "El hombre es una maroma tendida entre el animal y el superhombre". Cfr. Invitación a filosofar, Vol. 1, pp. 2-3.

8. Invitación a filosofar, pp. 13-14.

9. Ibidem, p. 21. 
10. Cfr. Beorlegui, C., "El carácter vectorial del alma y el sentido procesual de las relaciones alma-cuerpo en la antropología de J.D. García Bacca", Letras de Deusto, 14 , No. 30, 1984, pp. 5-26.

11. Ibidem, p. 22.

12. Jbidem, p. 24.

13. Ibídem, p. 17.

14. "Existencialismo", Xalapa, México: Universidad Veracruzana, 1962, p. 109.

15. "La idea de ser y eslar...", en Existencialismo, o.c., p. 16.

16. Cfr. Bcorlegui, C., "El carácter veclorial...", art. ya citado.

17. Cfr. entre otros textos, "Antropología filosófica contemporánea", Venezucla: Universidad Central de Venezuela, 1957; nueva edición en Barcelona, An/hropos, 1982; cfr. Cap. 5 .

18. Cfr. "Sobre el fondo filosófico de algunas tcorías de biología matemática", Theoría, Madrid, No. 3-4, 1952, pp. 113-120.

19. Cfr. "Los conceplos de Naturaleza, Técnica y Ciencia en el Renacimiento y en nuestros días", Caracas: Universidad Central de Venczucla, 1955.

20. México: F.C.E., 1963.

21. Caracas: Universidad Central de Venezuela, 1969.

22. Caracas: Universidad Central de Venezuela, 1972-73.

23. México: F.C.E., 1965.

24. Cfr. "Humanismo tcórico, práctico y positivo, según Marx", o.c., p. 14 y ss.

25. Estas Ires calegorías o niveles histórico-onlológicos las utiliza GB de una forma permanente, pero donde están más sistemáticamente utilizadas y explicitadas es en Curso sistemático de filosofia actual.

26. El sentido de actualidad (antropológica, científica, filosófica, social, etc.) se mide por su capacidad de hallarse, en cada uno de los ámbilos señalados, al nivel o en fase de "transustanciación".

27. Elogio de la técnica, Caracas: Monte Avila Ed., 1968; las cursivas son de GB.

28. Cfr. "Humanismo tcórico, práctico y positivo, según Marx", "Curso sistemático de filosofia actual" y "Lecciones de Historia de la filosofia".

29. "Humanismo teórico, práctico y positivo...", p. 51.

30. Cfr. "Curso sistemático...", p. 307.

31. "¿Quê es Sociedad? (Ensayo de definirla científica y ontológicamente)", Sistema, 1974, No. 4, pp. 7-21.

32. "Lecciones de Hisloria de la Filosofia", Vol. Il, o.c., p. 831.

33. Cfr. "Curso sistemálico...", cap. $3^{\circ}$, parte 1', pp. 51 y ss.; "Lecciones de Historia de la Filosofía", Vol. II, p. 831.

34. "Lecciones de Historia de la Filosofía", Vol. II, p. 815.

35. Cfr. "Libertad, ¿para qué?", "Libertad y miedo a errar" y "Una vez más acerca de libertad e historia", en Ensayos, Barcelona: Península, 1970.

36. Cfr. "Lecciones de $\mathrm{H}^{\mathbf{}}$ de la Filosofía", Vol. II, p. 821.

37. Me remito a otros trabajos sobre el tema: García Bacca. La audacia de un pensar, Bilbao: Universidad de Deusto, 1988; "El humanismo utópico de García Bacca", Anthropos, Barcelona, No. 29-30, 1983, pp. 80-88; "La visión antropológica de J.D. García Bacca", Estudios Filośfiços, Valladolid, 35, No. 99, 1986, pp. 269-294.

38. Cfr. "Qué es Dios y quién es Dios", Barcelona: Anthropos, 1986; Vida, muerte e inmortalidad, Caracas: U.C.V., 1983. 
39. Barcelona, Anthropos, 1984.

40. Caracas, Josefina Bigott, Edit., 1984.

41. Barcelona, Anthropos, 1984.

42. "Tres ejercicios litcrario-filosóficos de Antropología", o.c., p. 231.

43. GB cita repelidas veces las palabras de Zoroastro: "¡Oh hombre!, eres instrumento de naturaleza osadísima: de la tuya", cfr. "Tres ejercicios lilcrario-filosóficos de Antropología", p. 251.

44. Cfr. "Infinito, transfinito, finito", o.c., cap. $2^{2}$.

45. "Llamemos cuerpo", dice GB, "a la realidad física percibida, vivida, por la muerte, consciente, natural. Y denominemos soma a la realidad física ocultada, simplificada por la mente natural, por cl alma; y vivida así por ella, sin conciencia natural de tal simplificación de la realidad de verdad de clla misma", en "Transfinito e inmortalidad", p. 48.

46. Cfr. "Muerte e inmortalidad", p. 157; "Transfinitud e inmortalidad", pp. 59 y ss.

47. Cfr. Antropología filos6fica contemporánea, Caracas: U.C.V., 1957; nueva cdic., Barcelona, Anthropos, 1982.

48. Cfr. "Introducción al filosofar", o.c., e "Introducción literaria a la filosofia", Caracas: U.C.V., 1964.

49. Cfr. Orlega y Gasset, J., La historia como sistema, Madrid: Espasa-Calpe, 1971.

50. Cfr. "Ciencia y Técnica actuales", en Ensayos, Barcelona: Península, 1970, pp. 184 195.

51. Cfr. "Ciencia y técnica actuales (con un poco de política y un poco de pedagogía)", en Ensayos, o.c., pp. 184-195.

52. Cfr. el prólogo de "Existencialismo", o.c.

53. Sobre la influencia de Ortega en GB, cfr. Beorlegui, Carlos, "La presencia de Ortega y Gasset en el pensamiento de García Bacca", Letras de Deusto, 18, No. 40, 1988, pp. 93-117.

54. Cfr. "Elogio de la técnica", Caracas: Monte Avila Ed., 1968; "Curso sistemático", o.c., 1969.

55. Cfr. "Curso sistemático de pensamiento actual", cap. 2 y "Elogio de la técnica". o.c.

56. Cfr. "Tres ejercicios literario-filosóficos de antropología", o.c.

57. Cfr. Beorlegui, C., "Garcia Bacca. La audacia de un pensar", o.c., p. 127.

58. Cfr. "Melafísica natural y estabilizada; metafísica espontánea", "Curso sistemático" y "Lecciones de Historia de la Filosofía", Vol. II, Cap. sobre Marx.

59. Cfr. "¿Qué es Sociedad? (Ensayo de defínirla científica y ontológicamente)", o.c.

60. Cfr. sobre todo "Qué es Dios y quién es Dios".

61. Es una imagen que ha utilizado repetidas veces, aunque sólo con amplitud en "De Israel a Fanuel: de luchador con Dios a vidente de Dios", en "Existencialismo", pp. 233-242. Cfr. igualmente "Sobre virtudes y vicios", o.c., 1993, pp. 13-14.

62. Aunque en este amplio libro es donde desarrolla su pensamiento sobre Dios de forma expresa y amplia, inusual hasta ese momento, también se refiere a Dios de forma extensa en "Vida, muerte e inmortalidad", o.c., y "Filosoffa de la música", Barcelona: Anthropos, 1990.

63. Cfr. Habermas, J., "El discurso filosófico de la modernidad", Madrid: Taurus, 1989; Habermas, J. y cols., "Habermas y la modernidad", Madrid: Cátedra, 1988.

64. Cfr. Mardones, J.M., "Postmodernidad y cristianismo", Santander, Sal Terrae, 1988; Id, "Postmodernidad y ncoconservadurismo", Estella, Verbo Divino, 1991; Cortina, 
Adcla, "Razón comunicaliva y responsabilidad solidaria", Salamanca: Sigueme, 1985; Bcorlegui, Carlos, “La llustración en la encrucijada”, Letras de Deusto, 18, No. 41, 1988, pp. 9-32.

65. Es la misma fe que se encuentra presente en pensadores como Alvin Toffler, que creen que un mundo postindustrial será suliciente como para superar y dejar obsoletas las contradicciones del mundo industrial, donde se ha generado cl capitalismo y ha surgido, como réplica, el marxismo. "La terccra ola", Barcelona, Plaza y Janćs, 1980; "El «sohock»> del futuro", Barcelona, Plaza y Janés, 197I; "El cambio del poder", Barcelona, Plaza y Janés, 1990.

66. Su último libro, "Sobre virtudes y vicios" (1993), ya citado, no resuelve cslas interroganıes, más bien las ratifica. 